\title{
An Intuitionistic Fuzzy-based MCDM Approach For Location Selection Of Pilot Area For Green Roof Systems In Igdir Province, Turkey
}

\section{Seda TÜRK ${ }^{1 *}$}

\begin{abstract}
Green roof systems have been placed as the key to facilitating to mitigate the effects of climate change and weather effects on urban environmental conditions. Green roof systems are defined as sustainable systems due to fact that these systems improve building envelope performance along with many advantages such as improvement on air quality, reduction on carbon emission and mitigation of urban heat island. In addition, Igdir is one of the provinces with the highest carbon emission-environmental pollution in Turkey. Hence, green roof system infrastructure is critical to mitigating effects of anthropogenic emissions of carbon dioxide and other "greenhouse" gases in Igdir. In this study, an intuitionistic fuzzy-based multi-criteria decision making approach is proposed to evaluate 5 neighborhoods that have been selected according to population density to find out a pilot area for installation. Three main; economical, environmental and social, and 12 their corresponding sub-criteria are used and the results indicate that the approach indeed found out that Baglar neighbourhood is the best area as a pilot to build up a green roof system.
\end{abstract}

Keywords: Green roof system, Multi-criteria decision making (MCDM) method, Intuitionistic fuzzy sets, Location selection problem

${ }^{1}$ Seda TÜRK (Orcid ID: 0000-0001-9045-0694), Iğdır Üniversitesi, Mühendislik Fakültesi, Endüstri Mühendisliği Bölümü, Iğdır, Türkiye

*Sorumlu Yazar/Corresponding Author: Seda Türk, e-mail: seda.turk@igdir.edu.tr 


\section{INTRODUCTION}

Green roof is widely perceived as one of the most important solutions to mitigate climate change which causes increase of temperatures, drought, flooding in urban areas and air pollution in cities all over the world (Rosasco and Periri, 2019). Many researchers have been focused on green roofs in order to decrease the impacts of climate change in countries which have different climatic conditions (Berardi et al., 2014). Technological and economical aspects of these systems were investigated and it is found out those green roof systems able to save energy, to increase the building envelope performance and the quality of water run-off (Rosato et al., 2015; Coma et al., 2018). Green infrastructure also improves the air quality along with a decrease in carbon mass levels and urban heat island (Tan and Sia, 2005). It has positive impacts on human thermal comfort and some benefits on reduction on flood risks, carbon reduction and aesthetics (Razzaghmanesh et al., 2016). For long-term, there are several economic benefits of green roofs. For instance, efficiency of energy has risen along with thermal performance where winter heating decreased and summer cooling increased while there is a decrease on competitive life cycle costs due to better roof longevity. In addition, green roof provides extra space on the rooftop where people able to be interact and socialise and this adds more value into facilities for long-term even though short-term cost inefficiencies (Tabatabaee et al., 2019). Green roofs are able to decrease dust, particulate matter and smog in the environment This makes greenhouse gas emissions reduce. Electromagnetic radiation penetration is also decreased by green roofs (Herman, 2003). There are numerous benefits of green roof as explained above and Table 1 indicates them.

Table 1. Benefits of green roof systems (Onder, 2014; Rosasco and Periri, 2019; Tabatabaee et al., 2019).

\begin{tabular}{ll}
\hline Types & Benefits \\
\hline Ecological & Utilising storm water, \\
& Mitigating urban heat island effect, \\
& Improving the quality of air, \\
& Reducing noise, \\
& Reducing electromagnetic radiation, \\
& Developing waste diversion, \\
& Mitigating negative impacts of urbanization on birds. \\
\hline Economical & Increasing efficiency of energy, \\
& Increasing retention of water, \\
& Increasing roof longevity, \\
& Providing retardation of possible fire, \\
& Developing urban agriculture, \\
& Reducing tax, \\
& Increasing job employment. \\
& Improving building aesthetic, \\
& Improving urban aesthetic and biodiversity, \\
Social & Human thermal comfort, \\
& Proving extra space for socialising, \\
& Health. \\
\hline
\end{tabular}

Due to a number of benefits that green roof systems have, the number of cities which changed policies to support green roofs has been increased. Since the 1970s, German governments started to take green roof systems into the normal life affording certain amount of cost for each building which installed green roofs (Getter and Rowe, 2006). Financial support policies have been applied in many European countries such as Denmark, Austrian. In addition, there are few Asian countries which have 
developed policies to support green roof systems such as Singapore, Japan, Hong Kong while the USA and Canada have been provided monetary support to increase the number of green roofs installations (Brudermann and Sangkakool, 2017). In these countries, the constructions built up roof gardens are named as "Green Architecture" or "Sustainable Building" assessing them with a consideration of the various certifications. Green roof systems have been paid attention in Turkey nowadays, especially metropolitan cities such as Ankara and Istanbul. Figure 1 shows an example of a green roof installation in Istanbul. According to the work of Beyhan and Erbas (Beyhan and Erbas, 2013), this green roof system provides less dust environments, mitigation on ambient noise, water efficiency, decrease on the amount of waste water with an improvement of the roof thermal insulation. In addition, the shopping centre gained an aesthetic appearance. Although, there are few examples of green roof installations, it not yet widely dispersed in urban areas. A thorough review of previous studies on green roof systems, to the authors' knowledge, there is no research found on the eastern part of Turkey.
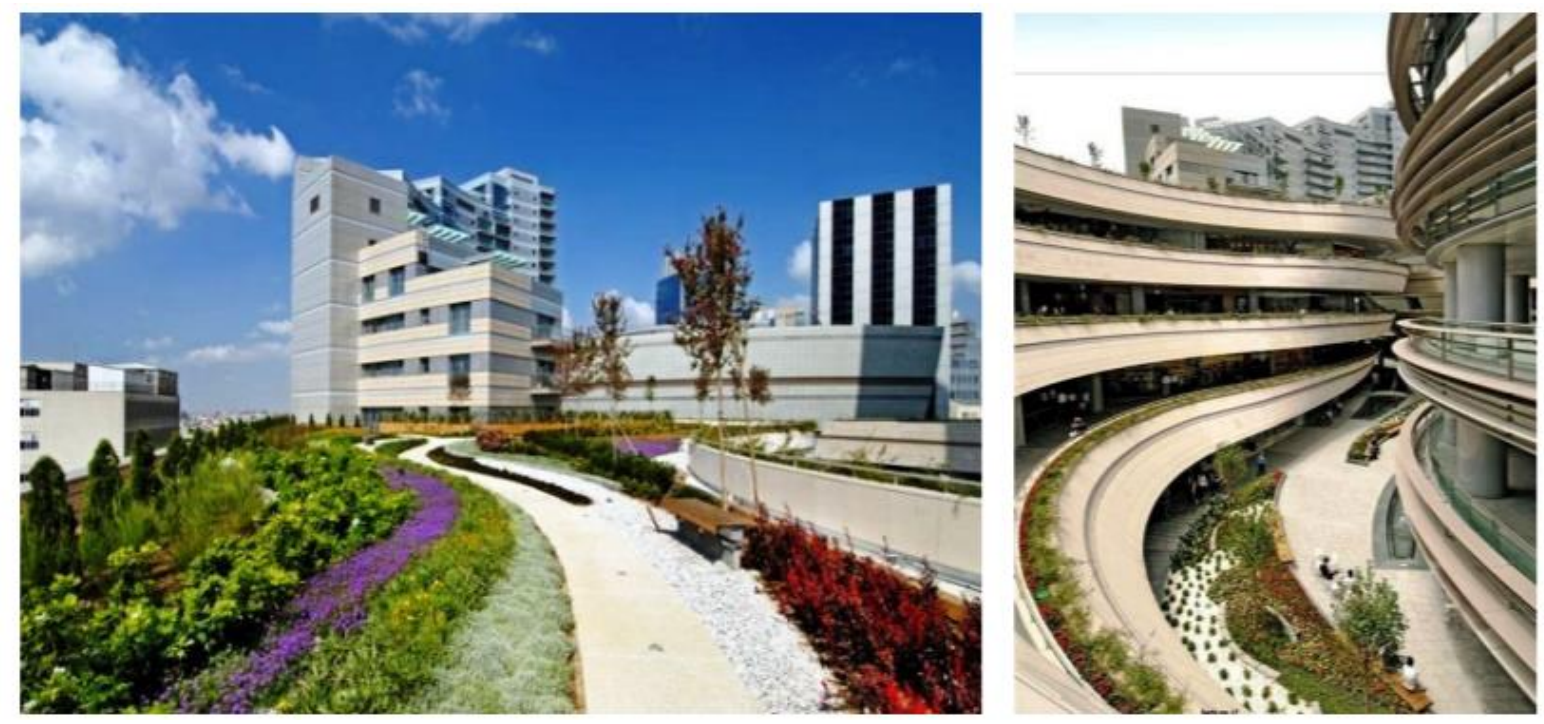

Figure 1. Kanyon Shopping Centre and Its Roof Garden, Istanbul (Beyhan and Erbas, 2013).

Igdir is one of the cities in the eastern part of Turkey and it has borders with three countries; Armenia, Nakhichevan and Iran. Igdir is closed to the Metsamor nuclear power plant in Armenia. Igdir province also surrounded by high-altitude areas such as Ararat Mountain. This leads Igdir has microclimatic aspects while surrounding cities have continental climate. This feature increases the variety of plants along with a high rainfall (Altikat, 2020). Despite the benefits derived from the location of Igdir, the air is not capable to disperse because of its location as in the middle of the bowl. This causes intensive air pollution and low air quality keeping polluted air on the city. The amount of particulate matter and dust are also high not to underestimate when the heating systems are on during winter (Sahin et al., 2020). Hence, the main objective of this study is to find out the best location to be a pilot area for green roof installations in Igdir province using an intuitionistic fuzzy-based multicriteria decision making (MCDM) approach.

Multi-criteria decision making methods consist of a number of approaches such as Analytic Hierarchy Process (AHP), Analytic Network Process (ANP), and Technique for Order Preference by Similarity to Ideal Solution (TOPSIS) and fuzzy sets. A MCDM method can also be integrated with other MCDM methods such as fuzzy AHP, AHP and TOPSIS. In addition, MCDM methods have been applied to a range of location selection problems such as solar power plant location selection using AHP (Turk and Sahin, 2020), underground storage site selection using fuzzy-Delphi methodology 
(Deveci, et al., 2018), ambulance location selection using interval type-2 fuzzy sets (Abdullah et al., 2017), hotel location selection using interval-valued intuitionistic fuzzy sets (Shou-Hsiung, 2018), electric vehicle charging stations selection using a Pythagorean fuzzy VIKOR method (Cui et al., 2018), shipyard location selection using a fuzzy ANP approach (Guneri et al., 2009), a healthcare facility location selection using a fuzzy TOPSIS approach (Mic and Antmen, 2019). The main factors that influence green roof adoption are investigated using a SWOT/AHP method in order to evaluate and determine factors for green roof systems in Thailand (Sangkakool et al., 2018). In this study, the green roof location selection problem is considered as a multi-criteria decision-making problem which consists of decision factors, criteria and alternatives. Due to the uncertain nature of the decision making process based on various criteria and their variability for green roof location selection and decision makers' subjective judgments, an intuitionistic fuzzy approach is proposed to solve the problem considering 3 main criteria and 12 sub-criteria.

The rest of the paper is structured as follows. Section "MATERIALS AND METHODS" describes the methodology for the intuitionistic fuzzy approach proposed and then explains the realworld problem with its description, the criteria selected and alternatives. Next, Section "RESULTS AND DISCUSSION" gives the results of the study. Finally, Section "CONCLUSION" concludes the study and proposes some potential future works.

\section{MATERIALS AND METHODS}

In this section, some definitions of an intuitionistic fuzzy set and multi-criteria decision making (MCDM) procedures are provided.

\section{Intuitionistic fuzzy sets}

Atanassov (Atanassov, 1986) introduced an intuitionistic fuzzy set (A-IFS) characterized by a membership function and a non-membership function. Membership degree and non-membership degree of each element are considered in A-IFS. This provides not to lose accuracy of fuzzy sets simply and detects inconsistencies in evaluation of each element (Gau \& Buehrer, 1993; Wang and Li, 2019). For this reason, in this study, an intuitionistic fuzzy set approach is used and necessary explanations and definitions are given in the followings:

Definition 1: A fuzzy set $\tilde{S}$ in a universe of discourse A is expressed as:

$$
\tilde{S}=\left\{\left(a, \mu_{\widetilde{S}}(a)\right) \mid \forall a \in A\right\}
$$

where $\mu_{\widetilde{S}}(a): a \rightarrow[0,1]$ is a membership value of a fuzzy set $\tilde{S}$ (Zadeh, 1975).

Definition 2: An intuitionistic fuzzy set (IFS) $\tilde{S}$ is expressed as:

$$
(\mathrm{IFS}) \tilde{S}=\left\{\left(a, \mu_{\widetilde{S}}(a), v_{\tilde{S}}(s)\right) \mid \forall a \in A\right\}
$$

where $\mu_{\widetilde{S}}(a): a \rightarrow[0,1]$ and $v_{\widetilde{S}}(a): a \rightarrow[0,1]$ providing the condition of $0 \leq \mu_{\widetilde{S}}(a)+v_{\widetilde{S}}(a) \leq 1$ for each element $a$ in the universe of discourse A for a fuzzy set (IFS) $\tilde{S}$. $\mu_{\widetilde{S}}(a)$ is defined as the degree of membership while $v_{\widetilde{S}}(a)$ express the degree of non-membership (Atanassov, 1986).

Definition 3: The intuitionistic fuzzy hesitation (the non-determinacy) degree $\pi_{\widetilde{S}}(x)$ is expressed as:

$$
\pi_{\widetilde{S}}(a)=1-\mu_{\widetilde{S}}(a)-v_{\widetilde{S}}(a)
$$


So, an intuitionistic fuzzy set can be indicated as: (IFS) $\tilde{S}=\left(\mu_{\widetilde{S}}(a), v_{\widetilde{S}}(a), \pi_{\widetilde{S}}(a)\right)$ (Atanassov, 1986). The algebraic operations used in this study are indicated in the followings for two intuitionistic fuzzy sets $\tilde{S}=\left(\mu_{\widetilde{S}}(a), v_{\widetilde{S}}(a), \pi_{\widetilde{S}}(a)\right)$ and $\widetilde{M}=\left(\mu_{\widetilde{M}}(a), v_{\widetilde{M}}(a), \pi_{\widetilde{M}}(a)\right) \quad$ in the universe A (Atanassov, 1986):

1. $\tilde{S} \otimes \widetilde{M}=\left\{\left(\mu_{\widetilde{S}}(a) \mu_{\widetilde{M}}(a)\right),\left(v_{\widetilde{S}}(a)+v_{\widetilde{M}}(a)-v_{\widetilde{S}}(a) v_{\widetilde{M}}(a)\right),\left(1-\mu_{\widetilde{S}}(a) \mu_{\widetilde{M}}(a)-\right.\right.$ $\left.\left(v_{\widetilde{S}}(a)+v_{M}(a)-v_{\widetilde{S}}(a) v_{\widetilde{M}}(a)\right)\right\}$,

2. $\tilde{S}^{\delta}=\left(\left(\mu_{\widetilde{S}}(a)^{\delta}, 1-\left(1-v_{\widetilde{S}}(a)\right)^{\delta},\left(1-v_{\widetilde{S}}(a)\right)^{\delta}-\mu_{\widetilde{S}}(a)^{\delta}\right), \quad \delta>0\right.$,

3. $\delta \tilde{S}=\left(1-\left(1-\mu_{\widetilde{S}}(a)\right)^{\delta}, v_{\widetilde{S}}(a)^{\delta},\left(1-\mu_{\widetilde{S}}(a)\right)^{\delta}-v_{\widetilde{S}}(a)^{\delta}\right), \quad \delta>0$,

A normalised Euclidean distance introduced by Szmidt and Kacprzyk is used to calculate the distance between two intuitionistic fuzzy sets and intuitionistic fuzzy arithmetic weighted averaging operator is used to get an aggregated intuitionistic fuzzy decision matrix (Szmidt \& Kacprzyk, 2000).

Definition 4: Let consider $\tilde{S}_{1}, \tilde{S}_{2}, \ldots, \tilde{S}_{n}$ is an IFS where $\tilde{S}_{k}=\left(\mu_{\widetilde{S_{k}}}(a), v_{\widetilde{S_{k}}}(a), \pi_{\widetilde{S_{k}}}(a)\right)$ and $k=$ $1,2, \ldots, n$. The intuitionistic fuzzy arithmetic weighted averaging (IFWAA) operator is explained as:

$$
\begin{aligned}
\operatorname{IFWAA_{w}}\left(\tilde{S}_{1}, \tilde{S}_{2}, \ldots, \tilde{S}_{n}\right)=\sum_{k=1}^{n} w_{k} \tilde{S}_{k} \\
=\left(1-\prod_{k=1}^{n}\left(1-\mu_{\widetilde{S_{k}}}(a)\right)^{w_{k}}, \prod_{k=1}^{n}\left(v_{\widetilde{S_{k}}}(a)\right)^{w_{k}}, \prod_{k=1}^{n}\left(1-\mu_{\widetilde{S_{k}}}(a)\right)^{w_{k}}\right. \\
\left.-\prod_{k=1}^{n}\left(v_{\widetilde{S_{k}}}(a)\right)^{w_{k}}\right)
\end{aligned}
$$

where $w_{k}$ is the weight of $\tilde{S}_{k}$.

\section{Intuitionistic fuzzy membership functions}

In this study, importance of each criterion is rated using the linguistic terms "Very important (VI)", "Important (I)", "Medium (M)", "Unimportant (U)", "Very unimportant (VU)" as seen Table 2. The corresponding intuitionistic fuzzy sets are also shown in Table 2.

Table 2. Linguistic variables for evaluating each criterion (Mondal and Pramanik, 2004).

\begin{tabular}{ll}
\hline Linguistic variables & IFNs $(\boldsymbol{\mu}, \mathbf{v}, \boldsymbol{\pi})$ \\
\hline Very important (VI) & $(1,0,0)$ \\
Important (I) & $(0.75,0.20,0.05)$ \\
Medium (M) & $(0.50,0.40,0.10)$ \\
Unimportant (U) & $(0.25,0.60,0.15)$ \\
Very unimportant (VU) & $(0.10,0.80,0.10)$ \\
\hline
\end{tabular}

The performance evaluation of each alternative is done using the linguistic terms "Extreme high (EH)", "Very high (VH)", "High (H)”, "Medium high (MH)”, "Medium (M)”, "Medium low (ML)", "Low(L)", "Very low (VL)", "Extreme low (EL)" and Table 3 demonstrates the associated intuitionistic fuzzy sets for each term. 
Table 3. Linguistic variables for evaluating each alternative (Mondal and Pramanik, 2004).

\begin{tabular}{ll}
\hline Linguistic variables & IFNs $(\boldsymbol{\mu}, \mathbf{v}, \boldsymbol{\pi})$ \\
\hline Extreme high(EH) & $(0.95,0.05,0.00)$ \\
Very high(VH) & $(0.85,0.10,0.05)$ \\
High(H) & $(0.75,0.15,0.10)$ \\
Medium high(MH) & $(0.65,0.25,0.10)$ \\
Medium(M) & $(0.50,0.40,0.10)$ \\
Medium low(ML) & $(0.35,0.55,0.10)$ \\
Low(L) & $(0.25,0.65,0.10)$ \\
Very low(VL) & $(0.15,0.80,0.05)$ \\
Extreme low(EL) & $(0.05,0.95,0.00)$ \\
\hline
\end{tabular}

\section{Intuitionistic fuzzy-based MCDM approach}

In this section, the proposed approach is explained in the following:

1) 3 main and 12 sub-criteria are selected based on literature review and experts' opinions and their importance are defined using linguistic terms shown in Table 2.

2) These terms are converted into intuitionistic fuzzy sets multiplying each main criterion and its corresponding sub-criterion.

3) Performance of each alternative neighbourhood is evaluated in the same way explained above.

4) The performance of each alternative is multiplied by importance of each criterion in order to calculate the aggregate intuitionistic fuzzy decision matrix.

5) The aggregate weighted intuitionistic fuzzy super decision matrix is calculated using IFWAA operator shown in Equation 4.

6) Negative-ideal solution and positive-ideal solution for intuitionistic fuzzy sets are calculated as:

$\mathrm{I}^{+}{ }_{i}=\left(\mu_{\mathrm{I}^{+}}(x), v_{\mathrm{I}^{+}}{ }_{i}(x), \pi_{\mathrm{I}^{+}}(x)\right)$

$\mathrm{I}^{-}{ }_{i}=\left(\mu_{\mathrm{I}^{-}}{ }_{i}(x), v_{\mathrm{I}^{-}}(x), \pi_{\mathrm{I}^{-}}(x)\right)$

where $\mathrm{I}^{+}{ }_{i}$ and $\mathrm{I}^{-}{ }_{i}$ indicates an intuitionistic fuzzy positive-ideal solution and negative-ideal solution, respectively. Each ideal solution is found as:

$\mu_{\mathrm{I}^{+}}(a)=\left(\max _{j} \mu_{\tilde{s}_{i j}}(a) \mid \in A_{i}\right) ; v_{\mathrm{I}^{+}}(a)=\left(\min _{j} v_{\tilde{s}_{i j}}(a) \mid \in A_{i}\right)$;

$\mu_{\mathrm{I}^{-}}(a)=\left(\min _{j} \mu_{\tilde{s}_{i j}}(a) \mid \in A_{i}\right) ; v_{\mathrm{I}^{-}}(a)=\left(\max _{j} v_{\tilde{s}_{i j}}(a) \mid \in A_{i}\right)$

where $A_{i}$ is $\mathrm{i}^{\text {th }}$ criterion and $\tilde{S}=\left[\tilde{s}_{i j}\right]_{n p}$ is the aggregate weighted intuitionistic fuzzy decision matrix where $i, j$ represent the number of criteria and alternatives, respectively.

7) The intuitionistic fuzzy normalised Euclidean distance is used to calculate positive and negative distances.

8) Alternatives are ranked measuring the closeness confidents based on negative-ideal solution and positive-ideal solution.

\section{Criteria for Decision Making}

Although, there are many criteria defined in literature, in this study, 3 main; Economical (M1), Environmental (M2) and Social (M3), and 12 sub-criteria shown in Table 4 are identified according to literature review and expert opinion about green roof installation location selection problem. Each criterion is explained shortly in the following: 
Table 4. Main criteria and their corresponding sub-criteria used in this study.

\begin{tabular}{ll}
\hline Main Criteria & Sub-criteria \\
\hline Economical (M1) & Installation cost (C1) \\
& Maintenance and disposal cost (C2) \\
& Energy savings (C3) \\
& Increase in property value (C4) \\
\hline Environmental (M2) & Possible damage (C5) \\
& Reduction of electromagnetic radiation (C6) \\
& Safety and security (C7) \\
& Environmental awareness (C8) \\
\hline Social (M3) & The lack of respective skills (C9) \\
& Collaboration levels (C10) \\
& Aesthetic (C11) \\
& Health (C12) \\
\hline
\end{tabular}

Economical (M1) impacts of green roof systems have been studied by many researchers as explained in Introduction Section. In this study, four of them are selected considering the area that will be evaluated.

Installation cost (C1) is the cost paid to install the greenery system considering materials, labour, equipment (either rental or buy), transportation costs (Shafique et al., 2018). According to Perini and Rosasco, traditional roof costs varying from 80 to $100 € / \mathrm{m}^{2}$ while the cost of a green roof is changing between 139 and $249 € / \mathrm{m}^{2}$ (Perini and Rosasco, 2016).

Maintenance and disposal cost (C2) covers pruning, fertilizing, and repairing or replacing any elements belongs to the green roof. This cost is related to all cost within the life span of a green roof system where roof longevity is found as 40-45 years although in the conventional roof, it is about 20 years (Rosasco and Perini, 2019).

Energy savings (C3) is related to decrease on the energy demand for cooling and heating. Green roofs improve the thermal comfort saving electricity for cooling and sources of heating (Shafique et al., 2018).

Increase in property value (C4) is another positive impact on the buildings when a green roof is present. The value of property is increased due to the aesthetic factors and an extra space for socialising. For instance, using a green roof increases the price of renting a flat by $16.2 \%$ in New York (Ichihara and Cohen, 2011).

Environmental (M2) impacts of green roof systems are too important to underestimate. There are a number of positive effects varying from air quality to control of storm water as seen Table 1. Despite them, there are some negative aspects which need to consider evaluation of a possible location. In this study, four criteria which covers both effects are chosen.

Possible damage (C5) could be naturally caused by wind, rain and sun. The damage can be mechanical or structural and it arising from nature and the quality or weakness of installations can be defined in possible damage for green roof features (Vijayaraghavan, 2016).

Reduction of electromagnetic radiation (C6): It is proven that green roof systems mitigate the electromagnetic radiation caused by base-stations involved in telecommunications by $99.4 \%$ (Herman, 2003). In addition, it is effective to reduce ultraviolet radiation.

Safety and security (C7): Protecting infrastructure from hazards and maintaining equipment securely is necessary for establishment for any facility. In addition, issues on occupational health and safety are planned at the design stage and it is very important to be able to maintain it. 
Environmental awareness (C8) should be increased among dwellers and other stakeholders to increase investment on green roofs. Lack of environmental awareness of green roof among urban planners, investors and city dwellers causes not to notice that green roof is one of the approaches for the sustainable environment. Low motivation in state and private sectors can also be recognised because of costs of green roof technology (Rahman et al., 2013).

Social (M3) impacts of green roofs varying from aesthetic to biodiversity can be listed as in Table 1. Green roofs improve social welfare providing extra green space where people are able to socialise and to relief in urban areas.

The lack of respective skills (C9) is one of the essential criteria for selecting the right location for green roofs system due to the difficulties causing in building infrastructure (Rosasco and Perini, 2019).

Collaboration levels (C10) is important to the progress of the work and the collaboration between stakeholders that consists of architects, civil engineers, environmental engineers, and dwellers (Shafique et al., 2018). The weakness member of stakeholders defines the quality of collaboration.

Aesthetic (C11) is related to the presence of green roofs which makes residents or neighbours pleased and it is completely about physical appearance of either buildings or city. Aesthetics for green roofs can be divided into two groups; building aesthetic and urban aesthetic. In general, green roofs provide green spaces that have panoramic views of their surroundings and are cultivated (Rosasco and Perini, 2019).

Health (C12): Green roof systems reduce pollution and increase the quality of water. That makes demands of healthcare decrease in a long term. Green roofs also help mental health of citizen providing them community hubs, social activities (Onder, 2014).

\section{Alternative locations}

There are 24 neighborhoods in the centre of Igdir. Due the fact that some neighborhoods have low population, I selected the 5 neighborhoods with the highest population density namely; Baglar (A1), Ozgur (A2), Topcular (A3), Emek (A4) and Karaagac (A5) as seen in Figure 2. In this study, each neighbourhood will be evaluated with respect to 3 main and 12 sub-criteria defined in the previous sub-section.

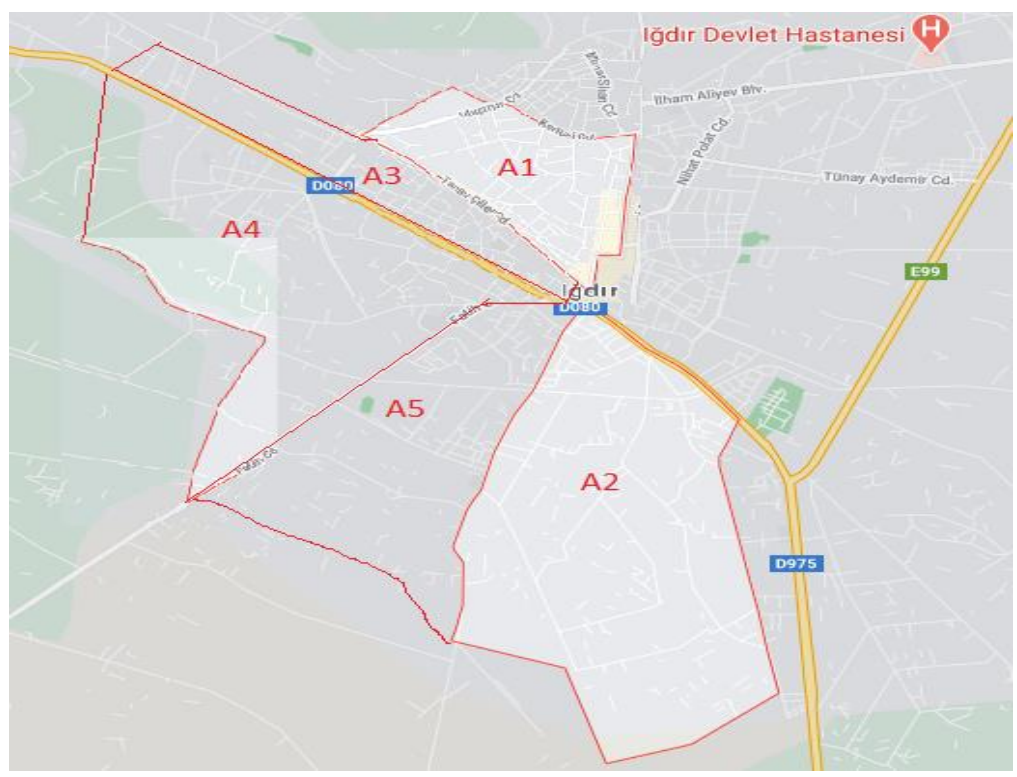

Figure 2. Neighborhoods map of Igdir for 5 alternatives. 


\section{Application of an intuitionistic fuzzy-based MCDM approach}

In this section, the proposed approach is explained in the following:

1) 3 main and 12 sub-criteria selected are evaluated in terms of their importance using linguistic terms. Table 5 indicates linguistic evaluation of importance of each criterion.

Table 5. Linguistic evaluation of importance of criteria and their corresponding intuitionistic fuzz sets.

\begin{tabular}{lll}
\hline Criteria & Linguistic term (Abb.) & Its corresponding fuzzy set \\
\hline M1 & VI & $(1,0,0)$ \\
M2 & I & $(0.75,0.20,0.05)$ \\
M3 & I & $(0.75,0.20,0.05)$ \\
C1 & M & $(0.50,0.40,0.10)$ \\
C2 & M & $(0.50,0.40,0.10)$ \\
C3 & VI & $(1,0,0)$ \\
C4 & VI & $(1,0,0)$ \\
C5 & VI & $(1,0,0)$ \\
C6 & VI & $(1,0,0)$ \\
C7 & VI & $(1,0,0)$ \\
C8 & I & $(0.75,0.20,0.05)$ \\
C9 & I & $(0.75,0.20,0.05)$ \\
C10 & I & $(0.75,0.20,0.05)$ \\
C11 & U & $(0.25,0.60,0.15)$ \\
C12 & M & $(0.50,0.40,0.10)$ \\
\hline
\end{tabular}

2) These terms are converted into intuitionistic fuzzy sets multiplying each main criterion and its corresponding sub-criterion. For instance, the importance of installation cost $(\mathrm{C} 1)$ is multiplied by Economical (M1) criterion and new (C1) is occured as seen in Equation 8.

$$
M 1 \otimes C 1=(1,0,0) \otimes(0.50,0.40,0.10)=(0.50,0.40,0.10)
$$

Table 6. Linguistic evaluation of alternatives in terms of criteria

\begin{tabular}{lllllll}
\hline Alternatives & C1 & C2 & C3 & C4 & C5 & C6 \\
\hline A1 & H & H & H & VH & ML & VH \\
A2 & VH & VH & MH & M & VH & EH \\
A3 & H & H & H & VH & M & VH \\
A4 & H & H & H & H & M & EH \\
A5 & VH & VH & MH & M & VH & VH \\
\hline Alternatives & C7 & C8 & C9 & C10 & C11 & C12 \\
\hline A1 & H & VH & H & H & VH & VH \\
A2 & M & ML & H & ML & MH & MH \\
A3 & MH & MH & H & H & MH & H \\
A4 & MH & H & H & M & VH & H \\
A5 & M & ML & H & ML & H & H \\
\hline
\end{tabular}

Table 7. Linguistic evaluation of alternatives in terms of installation cost (C1) and their corresponding intuitionistic fuzz sets.

\begin{tabular}{lll}
\hline Alternatives & Linguistic term (Abb.) & Its corresponding fuzzy set \\
\hline A1 & H & $(0.75,0.15,0.10)$ \\
A2 & VH & $(0.85,0.10,0.05)$ \\
A3 & H & $(0.75,0.15,0.10)$ \\
A4 & H & $(0.75,0.15,0.10)$ \\
A5 & VH & $(0.85,0.10,0.05)$ \\
\hline
\end{tabular}


3) Performance of each alternative neighbourhood is evaluated in terms of each criterion in the same way explained above as seen in Table 6 and Table 7 shows performance of alternatives for installation cost $(\mathrm{C} 1)$ as an example and the rest evaluation is done in the same way.

4) The performance of each alternative is multiplied by importance of each criterion in order to calculate the aggregate intuitionistic fuzzy decision matrix.

5) The aggregate weighted intuitionistic fuzzy super decision matrix is calculated using IFWAA operator shown in Equation 4.

6) Negative-ideal solution and positive-ideal solution for intuitionistic fuzzy sets are calculated as seen Table 7.

7) The intuitionistic fuzzy normalised Euclidean distance is used to calculate positive and negative distances and values found are shown in Table 8.

8) Alternatives are ranked measuring the closeness confidents based on negative-ideal solution and positive-ideal solution as seen in Table 8.

\section{RESULTS AND DISCUSSION}

Table 8. Positive and negative ideal distances, closeness coefficients and rank of alternatives.

\begin{tabular}{lllll}
\hline Alternatives & Positive-ideal & Negative-ideal & Closeness Coefficients & Rank \\
\hline A1 & 0.3351 & 0.5046 & 0.6009 & $\mathbf{1}$ \\
A2 & 0.4976 & 0.3370 & 0.4038 & 4 \\
A3 & 0.3627 & 0.4770 & 0.5680 & $\mathbf{2}$ \\
A4 & 0.3779 & 0.4631 & 0.5507 & $\mathbf{3}$ \\
A5 & 0.5037 & 0.3334 & 0.3983 & 5 \\
\hline
\end{tabular}

The results from the intuitionistic fuzzy approach is summarised in Table 8, providing values for positive-ideal solution and negative-ideal solution of each alternative and the rank of alternatives based on the value of closeness coefficients. It is shown that Baglar is the best neighbourhood alternative for placing green roofs with the crisp value of 0,6009 while the second best place namely Topcular is achieved 0,5680 crisp value. In addition, Baglar neighbourhood is differentiated from the other neighborhoods with its substantially larger green roofs space. In addition, Baglar consisting of new structures could be lead investors to build up green roof systems. In Baglar, income level and education level of neighbourhood residents are quite higher than others. Topcular is one of developed neighborhoods due to its location between Baglar and Emek. This makes it quite suitable for installation green roofs. Moreover, Emek neighbourhood is moderately appropriate as a potential location. The fact that a university campus is in this neighbourhood puts it in the 3rd rank even though it is close like Ozgur and Karaagaç and its poor performance in economic and social criteria. In addition, Ozgur and Karaagac are the worst options having quite close closeness coefficients values.

As the actions of small changes on the roof systems contribute substantially to economical impacts, in this study, it is clearly seen which economic aspects are received the necessary attention. Although installation cost could be higher than convenient roof systems, in a long term, it could be turned to an advantage and maintenance and disposal cost is worth to endure. In this study, more emphasis has been placed on short-term income. Therefore, energy savings (C3) and increase in property value (C4) are defined as "Very Important" and have played an essential role on Baglar becoming the best option and Topcular being the second best option. In addition, environmental impacts of green roof systems have been played a significant role on the result of this study. Three sub-criteria of Environmental (M2) impacts are defined as "Very Important" while the criterion of environmental awareness (C8) is received less attention by the decision maker. According to result found in this study, the linguistic values given for the importance of each criterion for environmental 
impacts are not similar and there is not much to observe considering each criterion separately as they interact with each other. Therefore, all criteria need to be considered together and the final ranking of alternatives is looked into.

All over the world, the number of the cities which paid attention to the green roof systems has been increased. Some governments have released the policies which provide financial support to people who installed green roofs and these supports are increasing day by day. There are also several studies which evaluate economic benefits of green roof systems which are already installed. For instance, economic evaluation of green roof has been done in Hong Kong using two different scenario and it is found that the total annual monetary value of properties have been increased to 22.02 million dollars from 12.98 million dollars (to 18.33 dollars from 10.77 dollars per $m^{2}$ for each year) (Peng and Jim, 2015). Another work which evaluates five different typologies of green roofs in Europe shows that in warm climates, energy demand for cooling is strongly reduced up to 8 percentage while for in cold climates, winter heating need is decreased up to 5 percentage (Ascione et al., 2013). Despite these, in Turkey, green roof systems are not yet received the necessary attention. There are few installation can be found in metropolitan cities such as Ankara and Istanbul and these structures are not evaluated in terms of their economic, environmental and social benefits. Igdir is the city that placed the first in air pollution in Turkey. Therefore, this work is good attempt to fill an important gap in the literature.

\section{CONCLUSION}

Green roof systems have the potential to be an important part of sustainable systems that bring human and natural systems together. Green roofs reduce air pollution, noise pollution and the amount of waste water in terms of sustainable system. In addition, urban heat island effect can be taken under control using green roofs along with urban biodiversity. Hence, it is clearly seen that there are various benefits of green roofs on cities and the number of cities supporting green roofs have been increased day by day. In Turkey, there are few applications found in metropolitan cities such as Istanbul and Ankara. However, there has been no attempt to install green roofs in the rest of cities in Turkey yet Igdir is one of the cities that should have a green roof application because of fact that the level of air pollution is quite high according to the surrounding cities and the city has microclimatic aspects and this makes wide variety in vegetation and plants. Plant diversity will make it easier for the investor to choose the plant to be used on green roofs and encourage investors. For this reason, in this study, Igdir is selected to investigate using an intuitionistic fuzzy approach.

The proposed MCDM based intuitionistic fuzzy approach provides a feasible way to dealing with this location selection for green roof systems in Igdir. This work is also one of the first studies in the context of green roofs which mitigate impacts of climate change and air pollution in urban areas. In literature, there are few studies which assess benefits, opportunities, costs, and risk of green roofs. This study filled an important gap in the literature in terms of finding desirable places to build up green roofs. In addition, based on the same line of thinking as in green roof systems, the proposed approach could be improved taking the opinion of more professionals and academics. There are many different criteria could be considered, hence a survey can be organised with the relevant experts to determine the validity of existing criteria and to see whether any missing criteria for location selection of building which covers green roofs. In addition, other MCDM methods could be applied to the same problem to check consistency of the approach proposed in this study. 


\section{REFERENCES}

Abdullah L, Adawiyah CWR, Kamal CW, 2017. A Decision Making Method Based on Interval Type-2 Fuzzy Sets: An Approach for Ambulance Location Preference. Applied Computing and Informatics. 14. 10.1016/j.aci.2017.04.003.

Altikat A, 2020. Modeling air pollution levels in volcanic geological regional properties and microclimatic conditions. Int. J. Environ. Sci. Technol. 17: 2377-2384.

Ascione F, Bianco N, de' Rossi F, Turni G, Vanoli GP, 2013. Green roofs in European climates. Are effective solutions for the energy savings in air-conditioning?,Applied Energy 104:845-859.

Atanassov K, 1986. Intuitionistic fuzzy sets. Fuzzy Sets Syst. 20: 87-96.

Berardi U, Ghaffarian AH, Ghaffarian A, 2014. State-of-the-art analysis of the environmental benefits of green roofs. Appl. Energy 115: 411-428.

Beyhan F, Erbas M, 2013. A Study on Green Roofs with the Examples from the World and Turkey. Gazi University Journal of Science 26(2): 303-318.

Brudermann T, Sangkakool T, 2017. Green roofs in temperate climate cities in Europe - An analysis of key decision factors. Urban Forestry \& Urban Greening 21: 224-234.

Coma J, Perez G, Cabeza LF, 2018. Chapter 4.8-Life Cycle Assessment of Green Roofs. In Nature Based Strategies for Urban and Building Sustainability. Pérez, G., Perini, K., Eds. Butterworth-Heinemann: Oxford, UK, pp. 341-351.

Cui FB, Yoy XY, Shi H, Liu HC, 2018. Optimal Siting of Electric Vehicle Charging Stations Using Pythagorean Fuzzy VIKOR Approach. Mathematical Problems in Engineering:1-12.

Deveci M, 2018. Site selection for hydrogen underground storage using interval type-2 hesitant fuzzy sets. International Journal of Hydrogen Energy. 10.1016/j.ijhydene.2018.03.127.

Gau WL, Buehrer DJ,1993. Vague sets, IEEE Trans. Syst. Man Cybern 23: 610-614.

Getter KL, Rowe DB, 2006. The role of extensive green roofs in sustainable development. Hort Science 41 (5): $1276-1285$.

Herman R, 2003. Green roofs in Germany: yesterday, today and tomorrow. p. 41-45. In Proc. of 1st North American Green Roof Conference: Greening Rooftops for Sustainable Communities, Chicago. 29-30 May 2003. The Cardinal Group, Toronto.

Ichihara K, Cohen JP, 2011. New York City property values: what is the impact of green roofs on rental pricing? Lett Spat Resour Sci 4: 21-30.

Mic P, Antmen Z F, 2019. A Healthcare Facility Location Selection Problem with Fuzzy TOPSIS Method for a Regional Hospital. Avrupa Bilim ve Teknoloji Dergisi (16): 750-757.

Mondal K, Pramanik S, 2014. Intuitionistic Fuzzy Multicriteria Group Decision making Approach to Quality Clay-Brick Selection Problems Based on Grey Relational Analysis. Journal of Applied Quantitative Methods 9(2):35-50.

Onder S, 2014. Advances of Green Roofs for Environment in Urban Areas. Turkish Journal of Agricultural and Natural Sciences Special Issue: 2: 2068-2074.

Peng LLH, Jim CY, 2015. Economic evaluation of green-roof environmental benefits in the context of climate change: The case of Hong Kong, Urban Forestry \& Urban Greening 14(3): 554-561.

Perini K, Rosasco P, 2016. Is greening the building envelope economically sustainable? An analysis to evaluate the advantages of economy of scope of vertical greening systems and green roofs. Urban Forestry and Urban Green 20: 328-337.

Rahman SRA, Ahmad H, Rosley MSF, 2013. Green Roof: Its Awareness Among Professionals and Potential in Malaysian Market Procedia. Social and Behavioral Sciences 85: 443-453.

Razzaghmanesh M, Beecham S, Salemi T, 2016. The role of green roofs in mitigating Urban Heat Island effects in the metropolitan area of Adelaide, South Australia. Urban Forestry and Urban Green 15: 89-102. 
Rosato P, Valcovich E, Stival CA, Berto R, Cechet G, 2015. Horizontal extensive green roofs in existing buildings. Part one-Technological feature. Valori e Valutazioni Theories and Experiences 8: 29-44.

Rosasco P, Perini K, 2019. Selection of (Green) Roof Systems: A Sustainability-Based Multi-Criteria Analysis. Buildings 9(5): 134-151.

Sahin F, Kara MK, Koc A, Sahin G, 2010. Multi-criteria decision-making using GIS-AHP for air pollution problem in Igdir Province/Turkey. Environmental Science and Pollution Research 27: 36215-36230.

Sangkakool T, Techato K, Zaman R, Brudermann T, 2018. Prospects of green roofs in urban Thailand - A multi-criteria decision analysis. Journal of Cleaner Production 196: 400-410.

Shafique M, Kim R, Rafiq M, 2018. Green roof benefits, opportunities and challenges - A review, Renewable and Sustainable Energy Reviews 90: 757-773.

Shou-Hsiung C, 2018. Autocratic multiattribute group decision making for hotel location selection based on interval-valued intuitionistic fuzzy sets. Information Sciences. Volume 427:77-87.

Szmidt E, Kacprzyk J, 2000. Distances between intuitionistic fuzzy sets. Fuzzy Sets and Systems 114 (3): 505-518.

Tabatabaee S, Mahdiyar A, Durdyev S, Mohandes SR, Ismail S, 2019. An assessment model of benefits, opportunities, costs, and risks of green roof installation: A multi criteria decision making approach. Journal of Cleaner Production 238: 117956-117969.

Tan PY, Sia A, 2005. A pilot green roof research project in Singapore. In Proceedings of the Third Annual Greening Rooftops for Sustainable Communities Conference. Toronto, ON, Canada, 4-6 May 2005.

Turk S, Sahin G, 2020. Corrigendum to "Multi-criteria decision-making in the location selection for a solar PV power plant using AHP” [Measurement 129 (2018) 218-226], Measurement, Volume 153.

Vijayaraghavan K, 2016. Green roofs: A critical review on the role of components, benefits, limitations and trends. Renewable and Sustainable Energy Reviews 57: 740-752.

Wang B, Li JY, 2019. Model for evaluating the enterprise financial performance with interval-valued intuitionistic uncertain linguistic information. Journal of Intelligent and Fuzzy Systems 37 (2): 15871596.

Zadeh L, 1975. The consept of a linguistic variable and its applications to approximate reasoning. Inform Science 8:199-249. 